\title{
Material Comparative Study of 4 Stage Gear Box Housing Using Fea Methodology
}

\author{
N.Elumalai ${ }^{1}$, R.Manikandan ${ }^{2}$, M.K.Karthik ${ }^{2}$ \\ 1, 2,3 Assistant Professor, Department of Aeronautical Engineering, Bharath Institute of Higher Education and \\ Research, Chennai.
}

Article History: Received: 11 January 2021; Accepted: 27 February 2021; Published online: 5 April 2021

ABSTRACT: The material comparative study of the product is used to reduce the weight of the product and then
structural strength improvement, four stage gear box mostly used in the light vehicles like car and small Omni
vehicles, gear box is the component give the more weight in the vehicle, gear box weight reduction and structural
stability can be analyze through FEA methodology in ANSYS software Keywords: FEA, Gearbox, Light vehicles, GFRP

\section{Introduction:}

The gear box is enclosed with the housing is named as gear housing. Gear housing is provided in the engine section to support the rotating components as well as to protect internal parts from external disturbances and it will act as a liquid tight container to keep the lubricant of the components within the gear box.

The gear box housing is an important component like shafts and gears. Because of its important the three stage Industrial Helical gearbox housings taken into Finite Element Analysis. The gearbox casing was drawn by using creo 2.0 and the pre-processing was done by Hyper mesh 11.0 and static and dynamic analysis done with help of Ansys 14.5. Gearbox casing can withstand more weight because of it's high strength ,so it is taken into account during preprocessing stage.

The aim of the static analysis is to predict the stresses and displacement value of end cover and gearbox casing. And the moto of the dynamic analysis to find the different mode shapes at different frequencies of gearbox casing. To find the optimized design of gearbox, we did different geometry with different dimensions and results were taken for all the geometries until satisfactory values achieved. This iterative techniques helps to find out the efficient gearbox. To measure the safety of gearbox Finite Element Analysis was carried out.

Gearbox failure may happens due to various reasons like manufacturing defects, improper design, oil deficiency and excessive time at stoppage at heavy load. In this work different loading case was considered and static and dynamic analysis was performed with major challenges to avoid the gearbox failures.

This works deals with the study about dynamic analysis of gearbox housing by using FEA. The aim of the dynamic analysis is to determine the natural frequency of gearbox casing by applying Ansys software. The main objective of this work to do the static and modal analysis of the gearbox housing of Tata indigo cs vehicle. The theoretical modal analysis has to be validated with experimental results from Fourier frequency transformer (FFT) analysis. The main objective behind this analysis is to do a complete Finite Element Analysis of gearbox casing rather than iterative procedures and empirical formulae. The gearbox casing feels internal pressures like crank pressure and gear shaft pressure. To find the changes in the internal pressures light vehicle gearbox casing was designed and analysed. To minimize the stresses analysis were taken in three ways like design modification, without design modification material changing and with design modification and material change.

The natural vibration modes and the frequency of the gearbox casing was determined by using Ansys and FET analyzer. The important of determining the natural frequency of casing is to prevent the maximum amplitude. From the analysis results of natural frequencies range and maximum amplitude was obtained. This shows that some critical components with complex designs used in automotive and production units. The mass and stiffness matrices were determined by exploiting known rules. Using analytical approach both the experimental and theoretical closest results were obtained. During the vibration analysis the bolted regions lower and upper casing were considered as critical elements.

\section{MATERIAL SELECTION:}

Traditionally, gear box casing made from different materials like cast iron or cast aluminium using techniques like permanent mold casting or shell molding. Experimentally, though, composite materials have also been used 


\section{Cast Iron}

If the alloys contains more than $2 \%$ of carbon content the alloys comes under group of a iron carbon alloys. When material fracture happened, the fracture can be identified by seeing the colour changes. Crack will propagate straightly due to the presence of carbide particles as impurities incase of white iron. Incase of spherical graphite iron crack propagation will not happen because of the presence of nodules. Graphite flakes embedded .In gray cast iron, one crack will initiate a series of crack in random direction.

\section{GFRP}

Glass fiber reinforced plastic (GFRP) generally named as fiberglass is a synthetic amalgamated material made up of plastic and extremely fine fibers of glass. It is high strengthened composite material with low cost .

\section{Finite Element Methodology}

The FEM have the following three steps

- Modeling

- Meshing

- Analysis

\section{Modeling}

Ribbing is the important parametric quantity while designing gear box casing which is to obtain desired strength. The CAD dimensions of gearbox casing is, Length $1500 \mathrm{~mm}$ Width-550mm Height- $750 \mathrm{~mm}$

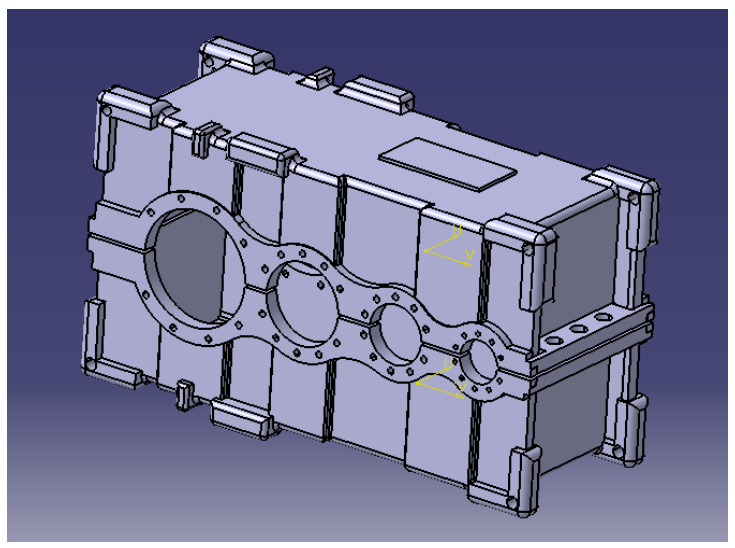

Fig 1: 3D Model of Gear Box Casing

\section{Meshing}

In FEM Methodology meshing is the main process the structural deformation and stress results can be easily identified through this mesh elements in this gear box casing tetrahedral element mesh created with the nodes of 181093 and elements of 100509.

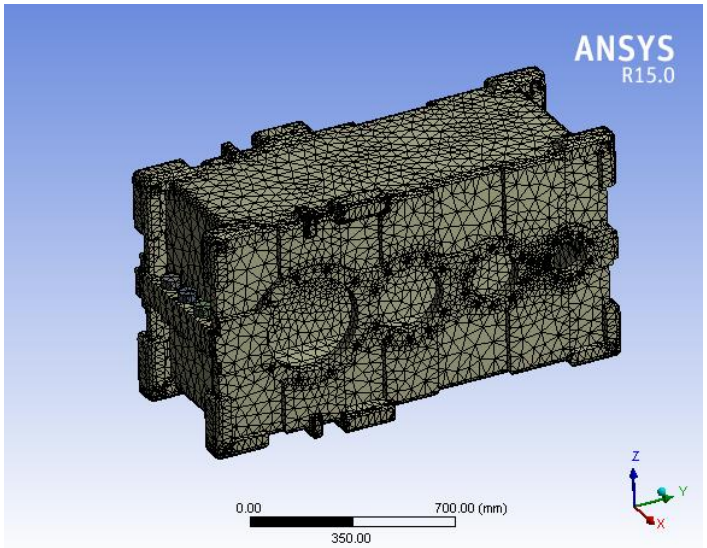

Fig 2: MESH MODEL OF GEAR BOX 


\section{Analysis}

The finite element analysis structural boundary conditions of fixed support and four gear fixing portions loads were applied static structural module in ANSYS Workbench.

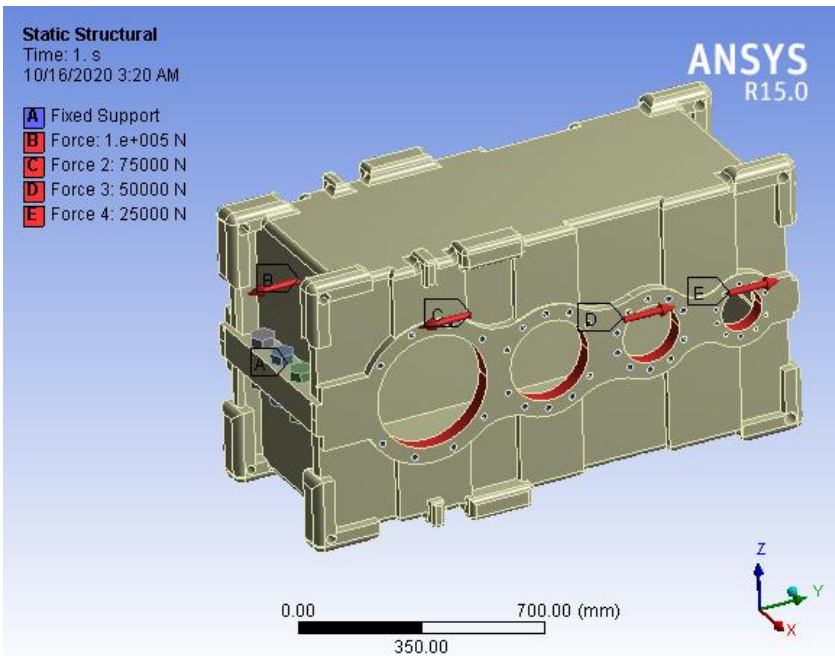

Fig 3: Structural Boundary Conditions of Gear Box Casing

\section{RESULTS AND DISCUSSION}

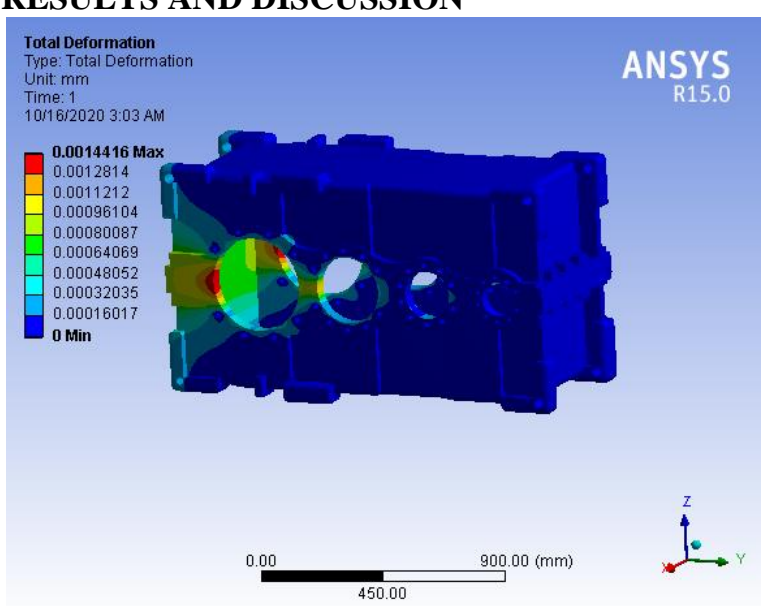

\section{CAST IRON}

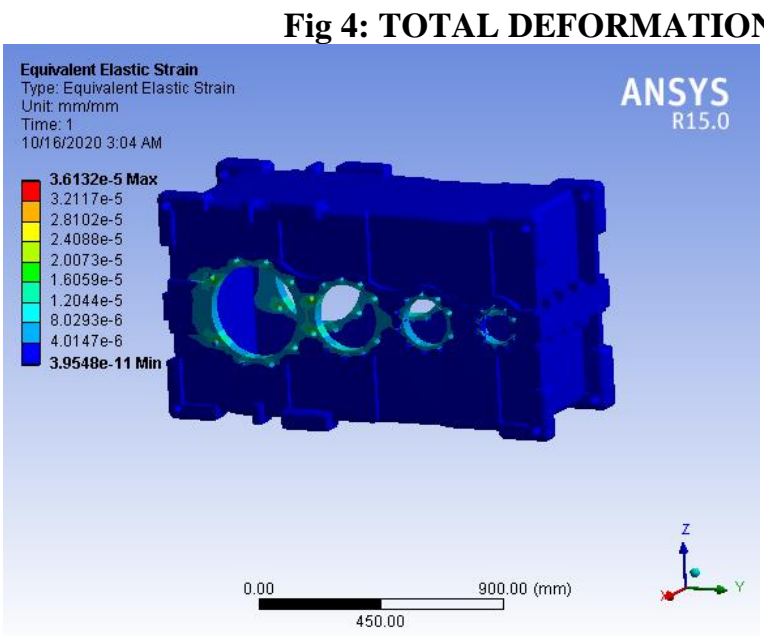

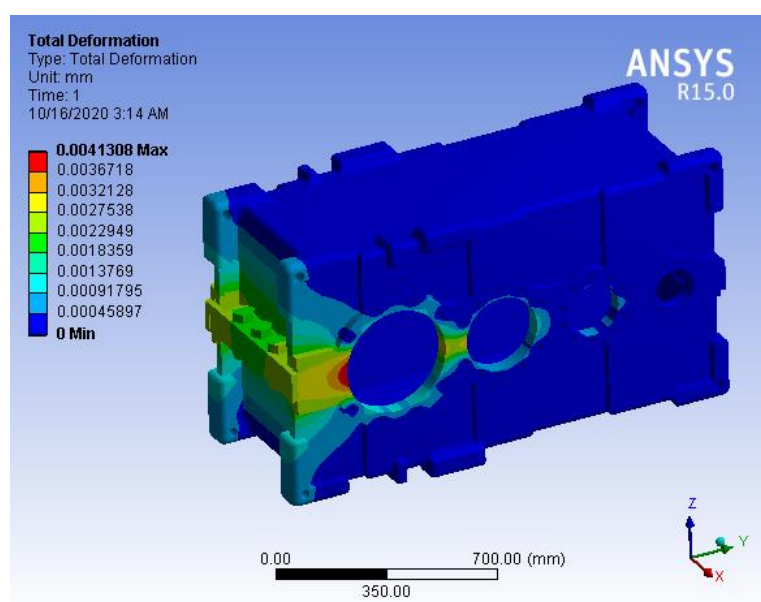

GFRP 
Fig 5: STRAIN RESULTS OF GEAR BOX CASING

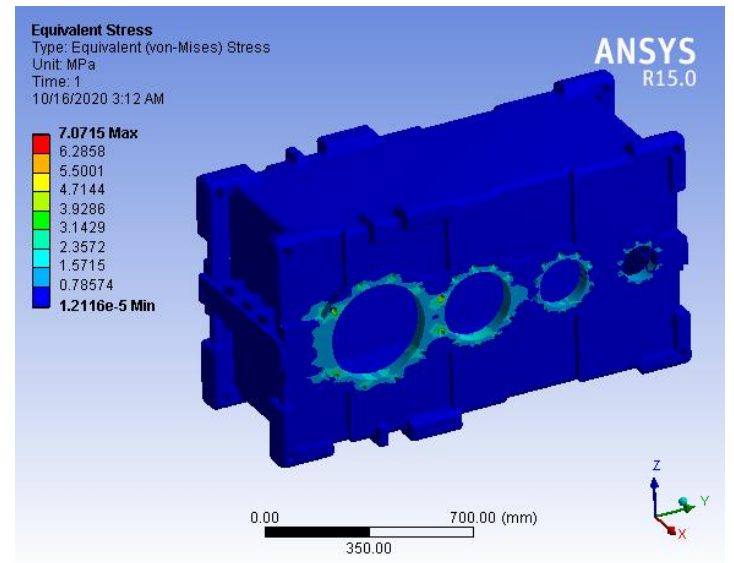

CAST IRON

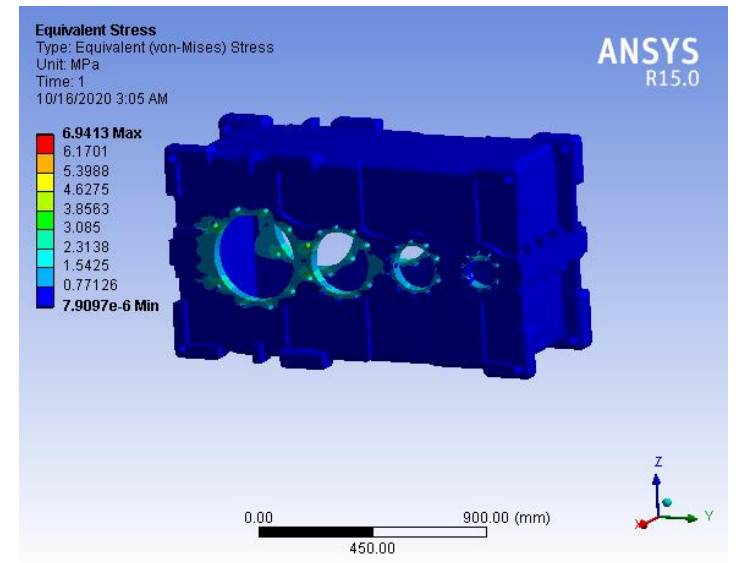

GFRP

Fig 6: STRESS RESULTS OF GEAR BOX CASING

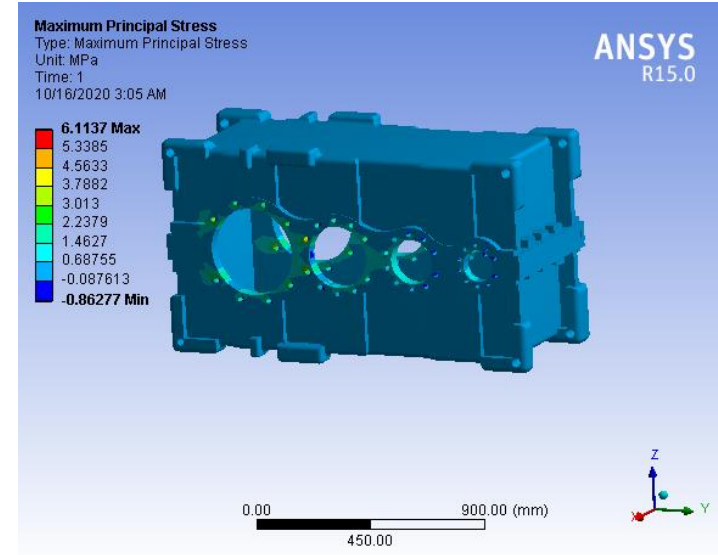

CAST IRON

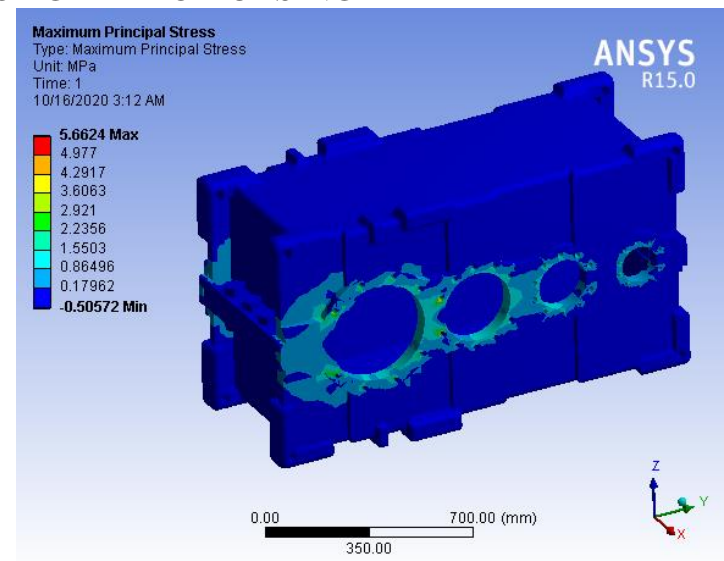

GFRP

Fig 6: PRINCIPLE STRESS RESULTS OF GEAR BOX CASING

\section{CONCLUSION:}

The material comparative study of gear box casing done in ANSYS Workbench with existing cast iron material is replaced by GFRP Material, weight reduction from cast iron to GFRP is $20 \mathrm{~kg}$ difference will give, cast iron gear box casing is $44.26 \mathrm{~kg}$ and GFRP weight is $22.26 \mathrm{~kg}$ the structural performance GFRP material got low stress of 6.9413MPa but in Cast iron produce 7.0175MPa so the GFRP material is the better replacement for GEAR Box casings

\section{REFERENCES}

1. Vasim Bashir Maner, M. M. Mirza, Shrikant Pawar Design Analysis and Optimization for Foot Casing Of Gearbox 3rd Irf International Conference, 10th May-2014, Goa, India.

2. Shrenik M. Patil 1, Prof. S. M. Pise Modal And Stress Analysis Of Differential Gearbox Casing With Optimization Nov-Dec 2013 At Int. Journal Of Engineering Research And Application.

3. R.V.Nigde, Prof. T.A.Jadhav, A.M.Bhide VibrationAnalysis of Gearbox Top Cover International Journal of Innovations in Engineering and Technology (IJIET)

4. Nitin S. Ghokhale PracticalFinite Element Analysis, 2008

5. J.K. Gupta R.S. Khurmi, A Textbook Of Machine Design Eurasia Publishing House, 2005

6. Ashwani Kumar* and Pravin P Patil "Dynamic Vibration Analysis of

7. Heavy Vehicle Truck Transmission Gearbox Housing Using FEA". (2014).

8. D.S.Chavan, A.K.Mahale, Dr.A.G.Thakur. "Modal Analysis of Power Take off Gearbox". (2013). 
9. Joule D, Hinduja S, Ashton J N, “Thermal analysis of spur gearbox Part 1: steady state finite element analysis", Journal of Mechanical Engineering, July 1988, pp.245-256

10. Joule D, Hinduja S, Ashton J N, "Thermal analysis of spur gearbox Part 2: transient state finite element analysis of the gearbox casing", Journal of Mechanical Engineering, July 1988, pp. 257-262

11. Wei FAN, Xin LIU, "Analysis on the Increasing Gearbox Cooling System of Wind Power Generator Based on ADINA”, Advanced Material Research vol.338 2011, pp. 185-188

12. Tushar. N. Khobragade, P. Priadarshni, "STATIC ANALYSIS OF GEARBOX CASING", Greaves Cotton Limited, Aurangabad. 